\title{
THE KANTIAN NOTION OF AESTHETIC JUDGMENT: THE BEAUTIFUL, THE SUBLIME, AND IMPORT FOR AESTHETIC LEARNING
}

\author{
IKE P. AGHAOSA
}

Department of Educational Foundations, University of Benin, Nigeria.

\begin{abstract}
This paper is sequel to "Philosophical, Professional and Epistemological Aesthetics: Nexus and Fundamental Issues and Arguments" (Aghaosa, 2014). Using the philosophical methods of language and logical analyses and arguments by analogy; and the methods of documentary inspection, the paper explored what should critically count as aesthetic judgment. Immanuel Kant's aesthetic judgment of the beautiful and the sublime provided the conceptual framework of analysis. Schopenhauer and Nietzsche's different hypothetical accounts from the phenomenological perspectives of these aesthetic categories helped to illustrate the effects of the beautiful and the sublime on the aesthetic spectator.
\end{abstract}

Keywords: Aesthetics, aesthetic judgment, the beautiful, the sublime, aesthetic spectator and emotions.

\section{Introduction}

Quite often, in casual conversations as well in some serious discourses, one would sometimes be assailed by any or all of these statements: "what a beautiful and pleasant lady!?"; "Such a handsome lad!"; "What a sublime emotional feeling Tchaikovsky's September 12 evokes on me whenever I listen to it"; "What a beautiful summer sunset"; "Oh! Look at that serene and beautifully mowed grass lawn in Mr. Noah's compound!"; "How graceful the gazelle moves!"; "what a grotesque looking wooden mask Jonah bought from Calabar!"; "That was a bizarre scene we watched in that horror movie!" "What a delightful and ecstatic feeling I really had at Jude's birthday party last Friday!" "Imagine the array of sumptuous delightful meals and fine tasting red and white wines that were served at the state governor's re-election victory party on Sunday". "What an awesome and rugged looking jeep automobile Tunde bought as a present for his wife on her fortieth birthday!" "Such a sweet-smelling white rose flower Richie presented to me on our maiden date!".

The above sample statements, carefully analyzed, will show that they are expressing sentiments, or facts (depending on one's perception and understanding) of aesthetic concepts and their approximate uses in expressing aesthetic emotions. Sometimes, certain statements of these hues are bull's eye hits in terms of aptly expressing what is intended; for example, "what a grotesque looking mask!" Some other expressions can and do create confusions in the perception of some listeners. For example, a man compliments a lady thus: "what a sweet soup you served me?" This is in spite of the fact that there was neither sugar nor honey in the said soup; and that the soup may be tangy and peppery in taste.

What these statements could and do imply is that philosophical aesthetics harbors numerous issues and arguments of which many lack consensual agreement. As a developing intellectual field, aesthetics requires what Broudy (1975) terms the development of appropriate aesthetic literacy using appropriate terminologies and vocabulary which can capture effectively the 
ontological essence of most aesthetic statements (p.102). Achieving this is an onerous task made sometimes more difficult by many individuals who, though they are intellectually sound in their different disciplines, but sometimes exhibit a high level of aesthetic illiteracy when confronted with aesthetics phenomena and analyses. This syndrome no doubt reflects the low level of perception of the aesthetic, aesthetic phenomena and emotion and the apt or appropriate linguistic terms to describe or designate them. On a further projection and extrapolation, the situation as earlier noted depicts the low level of attention accorded aesthetic education and learning in most societies' educational program. This often leads to Babel of voices about what actually is the aesthetic in terms of definition, phenomena categories and the appropriate aesthetic vocabularies to designate and express whatever that are impacted upon in any aesthetic encounter-individually or socially.

Epistemologically speaking, a generally low level of aesthetic literacy among a given cohort of population is also a reflection of the quality of the depth and breadth of immersion of aesthetic learning and exposure of the individuals concerned.

In an earlier study and report, this writer (Aghaosa, 2013) also undertook the task of defining and delineating aesthetics as a theory of human knowledge and knowing. This is as espoused by Baumgarten's (Gross, 2002) postulation on aesthetics and its link with philosophical and epistemological aesthetics. The crucial task here is to ascertain how the aesthetic can be identified, evaluated and categorized in human lives generally. What does it mean to say a phenomenon is beautiful or ugly? What kind of judgment are we making when aesthetic evaluations are made? In addition too, what are the appropriate terminologies that should be used to classify as well as express the aesthetic emotions elicited by every aesthetic phenomenon-natural or contrived?

In effect, the problem of this paper is a concern about how the aesthetic can be identified, evaluated and categorized in human as well as in as academic affairs generally. When we use the terms beautiful, handsome, sublime, aesthetic vehicles and emotions, what exactly do they connote? How do we come about such judgments? In other words what are essentially involved in aesthetic judgments and how are they carried out?

The purpose of this endeavor was to find out by what means aesthetic evaluationsjudgments- categorization and vehicles should be made. Should it be by empirical, intuitive, psycho motive means of knowing- solely of each or in combination of all these modes of knowledge and human knowing? .In other words, what specific human faculties and by how, are they used in gaining access and understanding of aesthetic phenomena-vehicles and emotions?

The significance of this paper will be determined by how far it would be able to:

i. provide an in-depth intellectual analysis and classification of the fundamental concepts, issues and arguments of professional and philosophical aesthetics;

ii. help provide informed opinions about how aesthetic terms/terminologies that describe the categories, vehicles and emotions of aesthetics should be appropriately used in aesthetic discourses generally; 
iii. highlight not only the crucial need to give adequate attention to philosophical and epistemological aesthetics in academic circles, but also assist in the growth of professional aesthetics-the practical aspects of aesthetics;

iv. help provide and engender the pre-requisite aesthetic literacy for aesthetic discourses and -analysis generally.; and

v. provide the essence and justification to promote the aesthetic enhancing subjects such as the visual, auditory, and dramatic arts (fine -arts, music and literary studies); the Humanities-History, languages and literature etc in Nigerian secondary for the development of aesthetic literacy among secondary school students.

This was essentially a qualitative based enquiry. It therefore relied on these theoretical and philosophical methodologies: language and logical analyses; and arguments by analogy. The survey proceeded in this sequence: there was first a purview of Immanuel Kant's thesis on aesthetic judgment which provided the theoretical framework of the work. This was followed by a detailed analysis of aesthetic judgment, aesthetic categories of the beautiful and the sublime. Finally, suggestions were proffered on how aesthetic learning endeavors could be pursued for the benefits of all in the society.

This survey, as much as possible, restricted itself to the issues of aesthetics and aesthetic learning and formal education. Its major focus was on the secondary level of Nigerian contemporary education system.

\section{Immanuel Kant and Aesthetic Judgment}

Immanuel Kant gave high regard for our mental faculty of reason which he asserts "invests the world with structure" (Internet Encyclopedia of Philosophy, 2000). In his works on aesthetics and teleology, he argues that it is our faculty of judgment that enables us to have experience of beauty, and grasp those experiences as part of an ordered, natural world with a purpose. Kant's work is referred to as Critical Philosophy. This is condensed in a triad: the Critique of Pure Reason; the Critique of Practical Reason; and the Critique of Judgment these most relevant to this survey.

The basic explicit purpose of Kant's critique of Judgment was to investigate whether the 'Power' (faculty) of judgment provided itself with an a'priori principle. He had hitherto assumed that judgment was just a name for the combined operation of other more fundamental faculties. But now, Kant has been led to speculate that the operation of judgment might be organized and directed by a fundamental a'priori principle that is unique to it. It is this that the critique of judgment sets to explore, the validity and implication of such hypothesis. (Internet Encyclopedia of Philosophy, 2000).

Judgment in Kant's definition is 'the subsumption of a particular under a universal is in general, the faculty of understanding is that which supplies concepts (universals), and reason is that which draws inferences (constructs syllogisms for example), then judgment 'mediates' between the understanding and reason by allowing individual acts of subsumption to occur. This leads Kant to a further distinction between determinate and reflective judgment. As elaborated, determinate judgment is fairly straight forward, for example, the sun is bright; 
while reflective judgment proceeds without concepts sometimes in order to form a new concept. This judgment forms a greater philosophical problem: how could a judgment take place without a prior concept? How can or how are new concepts formed? This is why for Kant aesthetic judgment is a particularly interesting form of reflective judgment. Elaborating, using investigation about art, beauty and the sublime partly as a way of illuminating judgment in general, Kant holds that: Aesthetic judgments exhibit in an exemplary fashion precisely, those features of judgment in general which allows us to explore the transcendental principles of judgment. But Kant had still higher concerns. The whole problem of judgment is important because judgment, Kant believes forms the motivating link between two great branches of philosophical inquiry, the theoretical and the practical. Kant notes that these two philosophical branches have completely different topics but paradoxically, these topics have as their object, the very same sensible nature. Theoretical philosophy has as its topic the cognition of sensible nature; practical philosophy, the moral action in and on sensible nature. (Internet Encyclopedia of Philosophy, 2000).

Since aesthetic judgments are a perfectly normal function of the same faculties of cognition, they will have the same validity as such ordinary acts of cognition. (Internet Encyclopedia of Philosophy, 2000).

Kant's analyses in the foregoing can be summarized as the harmony between and among faculties. Such a harmony (in the case of the beautiful) will be purposive but without a purpose. It will also be universal and necessary because it is derived from the universal common sense. Aesthetic judgment must be judgment in some sense: they are mental acts which bring a sensible particular under some universal. The mechanism of this judgment as analyzed is that:

.....Aesthetic judgment is a judgment of the presentation of a particular (singular) object; no particular, determination of either sensible intuition or understanding forms a necessary part of the judgment. In ordinary cognition of the world, this lack of restriction would be entirely out of place. It would be nonsense to judge whether a particular thing was a sofa without restricting my judgment to that particular thing and to the concept of sofa. However, considered in general (that their essence as sub faculties) the faculties of imagination and understanding are likewise not restricted to any presentation or kind of sense or concept. " (Internet Encyclopedia of Philosophy, 2000).

The presence of cognitive sub-faculties in their various relations (in all human beings) is equivalent with the principle of the universal communicability and validity (that is common sense) of any mental state in which these faculties are involved a'priori. In effect, aesthetic judgment rests upon the same unique conditions as ordinary cognition and thus, that the former must have the communicability and validity as the latter. It is just that presented with 
the beautiful, our cognitive faculties are released from limitations that characterize ordinary thoughts and produce what, above, we call a cascade of thoughts and feelings.

Most other works in the field of aesthetics have either attempted to critique or expand on themes developed by Immanuel Kant's Critique of Judgment. Schopenhauer, and to a large extent, Nietzsche (Vandenabeele, 2003: 90-106) from the phenomenological perspective even though they disagree with Kant in some aspects, have by explicating on some issues in the work, provided some meaningful insights into some pervasive problems in aesthetics. Schopenhauer, who holds the human will as the supreme motivator to power, sees the feelings of the beautiful as that point of contemplation where pure knowledge has gained the upper hand and not even a single recollection of the will remains. The change required for this is achieved through the elimination of all willing - in this state, contemplation and perception cannot proceed from the will. Epistemologically, this state of pure knowing from Schopenhauer's perspective is obtained first of all by a violent tearing away from the relations of the same objects to the will which are recognized as unfavorable, by a free exaltation accompanied by consciousness beyond the will and the knowledge related to it" (Vandenabeele, 2003: 90-106). For Nietzsche, the beautiful is "Apollonian feeling of harmony, discipline and pleasure: the object (of contemplation) invites us to feel disinterested Dionysian intoxication". In this state of Nietzsche's (Dionysian) intoxication, the subject contemplating is lost (Vandenabeele, 2003: 90-106). That is the self-forgetfulness and total self-destruction by becoming one with the whole of reality.

\section{The Kantian Category or Notion of the Sublime}

The other basic type or category of the aesthetic experience and judgment on the polar end of the beautiful is the sublime. The sublime is that which evokes surprise, awe, veneration etc in humans. There are two sub-categories of the sublime. They are: (a) The Mathematically Sublime: this is when our ability to intuit is overwhelmed by size e.g. a huge building, mountain, or an ocean. (b) The Dynamically Sublime. This is when forces e.g. a storm or speed overwhelm human intuition. As explained by Kant, the sublime is neither accompanied by the feelings of fear nor comfort. Interestingly, the sublime can be a pleasurable experience. The sublime feeling is therefore, a kind of 'rapid' alternation between the fear of the overwhelming and the peculiar pleasure of seeing that, overwhelming, overwhelmed. The sublime according to Schopenhauer is "that state of pure knowing that is obtained by a conscious and violent tearing away from the relations of the same object of the will which are recognized as unfavorable.... (Vandenabeele, 2003: 90-106).

In explaining essentially after Kant's notion of the sublime, Schopenhauer informs that the object can be hostile to the human will in two different ways: by their immensity or by their threatening power. The will-lessness and the disinterestedness - two typical characteristics of the Schopenhauerian aesthetic spectator in the beautiful seem to be absent in his account of the sublime. The sublime feeling for Schopenhauer epistemologically is ambivalent. The closest interpretation to this ambivalent (Vandenabeele, 2003: 90-106) sense of the sublime is perhaps implicit in the Igbo language phrase: "Ona hum uto" - pleasant painful feeling; or "it pains me sweet" For Nietzsche, from the Apollonian and Dionysian perspective, the aesthetically sublime is an excessive feeling either originating in qualitative excess 
(dynamically sublime) or in quantitative excess (mathematically sublime) which overwhelms the imaginative power of the spectator.

From the foregoing analysis and discussions, it is evidently clear that the issues of the beautiful and sublime (in addition to their varying intermediate categories) are the major preoccupation of aesthetic judgment both in philosophical as well as epistemological aesthetics. As was also noted, quite often, many individuals (spectators') attention are sometimes captivated by the most aesthetic phenomena which, in turn, also elicits aesthetic emotions from them. However, as may sometimes be noted, only some few aesthetically educated and exposed persons are usually able to describe the aesthetic emotions elicited in them by various aesthetic phenomena with the appropriately apt linguistic terminologies. In other words, those persons who are often unable to conveniently express themselves aptly i.e. communicate their aesthetic emotional impressions can be conveniently dubbed as 'aesthetic illiterates'. This is analogous to 'intellectual and numerical illiteracy'. The syndrome of 'aesthetic illiteracy' - very prevalent among many Nigerian school leavers from the basic to the tertiary rungs of the education system is often ignored by educationists generally and aesthetic educators in particular. The issue demands for concerted efforts by all stakeholders in Nigerian education to tackle and halt the further slide into 'aesthetic illiteracy'. This is a challenge to educational planners as well as aesthetic enhancing subjects' teachers in the country.

\section{Summary}

The question of what and how to evaluate aesthetic phenomena is as controversial as what definition can be given the term aesthetics. This is because almost every philosopher or artist tends to have their own perception and therefore, definition of the concept. This controversy of definition also plays out about how to evaluate and consequently pass judgments on aesthetic phenomena. Can aesthetic evaluation judgment be carried out or done in other types of evaluation say, for example, empirical judgment? Is it possible for two or more persons to have same or consensual agreement on particular aesthetic phenomenon, for example, a sculptural piece, a painting, landscape, ceramic, item, and even human beings? Supposing they can attempt, how should these be carried out, and in what aesthetic categories and relevant themes can they be expressed in. It is these questions that this paper dwelt upon and attempted to answer.

\section{Conclusion}

(a) Aesthetic judgment is a distinct type of judgment from empirical cognitive judgment even though they are both generically related. This is essentially from the mechanics of perception and judgment. This is because they (ordinary and aesthetic) both use essentially the same cognitive principles involved in ordinary as well as in aesthetic judgment. Aesthetic judgment(s) is well articulated in Immanuel Kant's conceptual framework for example when he asserts the disinterested pleasure - a transcendental means of perception that should appeal to the universality of human taste. This is in addition to the delineation of the aesthetic categories - principally, the beautiful and the sublime. 
(b) Schopenhauer, Nietzsche and other authors greatly influenced by the Kantian postulations on aesthetic judgment and categories, provide hypothetical accounts of the varying categories of the beautiful and sublime. So also were some empirical examples projected to drive home the point.

(c) There is also the plausibility that inadequate exposure of students at the basic level of Nigerian education could be responsible for the low rate of aesthetic literacy among many Nigerian school leavers. The direct consequences of this syndrome is often noticeable in the often obscure attempts by many Nigerians to appreciate and express their aesthetic emotions from contacts with aesthetic phenomena generally. The situation calls for a serious rethink about aesthetic learning in Nigerian education.

\section{Recommendations}

In the light of the foregoing, this study proposes the following.

(i) need for further in-depth analysis of aesthetic concepts, issues and arguments involved- they require rigorous examination;

(ii) much further investigations into other streams of aesthetics e.g. African, Asiatic and Anglo-American for better insights into the aesthetic equation for better enlightenment.

(iii) the urgent need and attention between and among philosophical, professional (artists) and epistemological aestheticians to collaborate more and perhaps make less abstract, aesthetic issue and concepts;

(iv) help promote aesthetic education and learning in the formal as well as informal fields of education generally;

(v) there will also be the need to evaluate the academic status of the various aesthetic literacy enhancing subjects such as the visual, auditory and dramatic arts; the humanities especially at the basic level of Nigerian education; and

(vi) for teachers of the aforementioned aesthetic enhancing subjects to consciously promote aesthetic literacy by emphasizing the use of appropriate aesthetic terminologies in delivering their lessons. Wrong of inappropriate use of aesthetic terminologies by students should be promptly corrected always.

\section{References}

Aghaosa, I. P. (2013). Philosophical, Professional and Epistemological Aesthetics: Nexus, Fundamental Issues, Arguments; and Challenges for Aesthetic Education. In Okuneye, O.R; Akinkuotu, Y. A.; Dansu, T. \& Jimoh, A S. (Eds.) Science and Development: A book of Readings in honour of Professor Emmanuel. O. Odubunmi. Lagos State University, Ojo, Lagos. Pp. 133 147.

Aghaosa, I.P. (2013). The Justification of Aesthetic Education in Nigerian Secondary Education"-yet to be published article.

Bell, C. (1974). The Aesthetic Hypothesis. in W. E. Kennick, (ed.) Art and Philosophy: Readings in Aesthetics New York: St. Martin's Press Inc. 
Broudy, H. S. (1975). The Aesthetic Dimension of Education in Educational Judgmentspapers in the Philosophy of Education. Editor: James J. Doyle. London: Routledge and Keegan Paulp102.

Gross, W. S. (2002). "The Neglected Programme of Aesthetics". British Journal of Aesthetics, 4 (4): 403-414.

Marchiano, G. "What to learn from Eastern Aesthetics" The Journal of Aesthetics Education 2 (10): 1-7.

Ogumor, (1993). Certificate Art for Junior and Senior Secondary Schools. Ibadan: university Press.

The Internet Encyclopaedia of Philosophy (2000). S.V. Immanuel Kant (1724-1804) Theory of Aesthetics and Teleology (The Critique of Judgment).

Vandenabeele, B. (2003). "Schopenhauer, Nietzsche and the Aesthetically Sublime" The Journal of Aesthetic Education, 37 (1): 90-106. 